\title{
Towards an integrated model for developing sustainable assessment skills
}

Citation for published version (APA):

Fastre, G. M. J., van der Klink, M. R., Sluijsmans, D., \& van Merrienboer, J. J. G. (2013). Towards an integrated model for developing sustainable assessment skills. Assessment \& Evaluation in Higher Education, 38(5), 611-630. https://doi.org/10.1080/02602938.2012.674484

Document status and date:

Published: 01/08/2013

DOI:

10.1080/02602938.2012.674484

Document Version:

Publisher's PDF, also known as Version of record

Document license:

Taverne

Please check the document version of this publication:

- A submitted manuscript is the version of the article upon submission and before peer-review. There can be important differences between the submitted version and the official published version of record.

People interested in the research are advised to contact the author for the final version of the publication, or visit the DOI to the publisher's website.

- The final author version and the galley proof are versions of the publication after peer review.

- The final published version features the final layout of the paper including the volume, issue and page numbers.

Link to publication

\footnotetext{
General rights rights.

- You may freely distribute the URL identifying the publication in the public portal. please follow below link for the End User Agreement:

www.umlib.nl/taverne-license

Take down policy

If you believe that this document breaches copyright please contact us at:

repository@maastrichtuniversity.nl

providing details and we will investigate your claim.
}

Copyright and moral rights for the publications made accessible in the public portal are retained by the authors and/or other copyright owners and it is a condition of accessing publications that users recognise and abide by the legal requirements associated with these

- Users may download and print one copy of any publication from the public portal for the purpose of private study or research.

- You may not further distribute the material or use it for any profit-making activity or commercial gain

If the publication is distributed under the terms of Article $25 \mathrm{fa}$ of the Dutch Copyright Act, indicated by the "Taverne" license above, 


\section{Assessment \& Evaluation in Higher Education}

\section{Towards an integrated model for developing sustainable assessment skills}

Greet M.J. Fastré , Marcel R. van der Klink, Dominique Sluijsmans \& Jeroen J.G. van Merriënboer

To cite this article: Greet M.J. Fastré , Marcel R. van der Klink , Dominique Sluijsmans \& Jeroen J.G. van Merriënboer (2013) Towards an integrated model for developing sustainable assessment skills, Assessment \& Evaluation in Higher Education, 38:5, 611-630, DOI: 10.1080/02602938.2012.674484

To link to this article: https://doi.org/10.1080/02602938.2012.674484

曲 Published online: 30 Mar 2012.

Submit your article to this journal $\widetilde{ }$

III Article views: 1070

Q View related articles $\sqsubset$

4 Citing articles: 6 View citing articles 


\title{
Towards an integrated model for developing sustainable assessment skills
}

Greet M.J. Fastréa,b*, Marcel R. van der Klink ${ }^{\mathrm{a}, \mathrm{c}}$, Dominique Sluijsmans ${ }^{\mathrm{a}, \mathrm{b}, \mathrm{d}}$ and Jeroen J.G. van Merriënboer ${ }^{a, b}$

${ }^{a}$ Centre for Learning Sciences and Technologies, Open University of The Netherlands, The Netherlands; ${ }^{b}$ Department of Educational Development and Research, Maastricht University, Maastricht, The Netherlands; ${ }^{c}$ Zuyd University of Applied Science, Heerlen, The Netherlands; ${ }^{d}$ Faculty of Education, HAN University, Nijmegen, The Netherlands

\begin{abstract}
One of the goals of current education is to ensure that graduates can act as independent lifelong learners. Graduates need to be able to assess their own learning and interpret assessment results. The central question in this article is how to acquire sustainable assessment skills, enabling students to assess their performance and learning throughout life, and preparing them to meet their own future learning needs. This article presents an integrated model for developing sustainable assessment skills, consisting of three components: conditions necessary for the development of sustainable assessment skills, elements of sustainable assessment and instructional methods for guiding students in the development of sustainable assessment skills. The article concludes with suggestions for future research to further develop the proposed model.
\end{abstract}

Keywords: sustainable assessment skills; lifelong learning; self-assessment; interpretation of assessment

In higher vocational education, there is increasing recognition that one of the main goals is to educate students to become independent and self-regulated lifelong learners (Boud and Falchikov 2006). Graduates must be prepared to cope with the challenging demands of rapidly changing professions. The necessity to improve transitions from higher education to the workplace and the need to better prepare students for future job demands have encouraged educational institutions to implement competence-based curricula. Such curricula focus on the development of professional skills rather than presenting diplomas based on completed courses, thereby replacing an emphasis on qualifications with an emphasis on capabilities (Biemans et al. 2004). Furthermore, a discipline-based approach is replaced by an integrated approach with a stronger focus on providing authentic learning experiences aimed at the development of competences needed for successful job performance (Tillema, Kessels, and Meijers 2000).

Competence-based education is expected to lead to a more gradual transition from education to workplace, but it does not necessarily imply that students are prepared for lifelong learning. Being a professional means having the ability not only to perform professional skills, but also to recognise when further improvement of

*Corresponding author. Email: greet.fastre@uhasselt.be 
one's own performance or the learning of new skills is required to meet the needs of a rapidly changing profession (McDonald et al. 1995; Regehr and Eva 2006). Learning can be formal, but also informal, and non-formal learning can help people improve their professionalism (Blair 2005). Students should learn professional skills, learn to deal with feedback from others and develop their own assessment skills that help them to recognise their learning needs and, eventually, to improve their performance. For example, student nurses must learn how to analyse a patient file and communicate with the patient at the same time (professional skills), but they should also recognise that they sometimes stop communicating because they are too focused on the patient file. This might be identified as a point of improvement (assessment skill). According to Boud (2000), students should develop sustainable assessment skills that enable them to assess their performance and to keep learning throughout life. Sustainable assessment can be defined as assessment that meets the needs of the present and prepares students to meet their own future learning needs (Boud 2000, 151). These assessment skills help students to become selfregulated learners who are aware of their own qualities and shortcomings and who know how to overcome possible hurdles (Butler and Winne 1995). To accomplish this, they should become responsible for their own learning and be treated as professionals right from the start of their higher vocational education (Nieweg 2004). However, at the start of an educational programme, students are often unable to take full responsibility for assessing their own learning and development because of their lack of expertise in the domain. The question arises as to how students can best be guided in the development of sustainable assessment skills.

This article starts with explaining the concept of sustainable assessment, followed by a comparison of summative and formative assessment, respectively. Subsequently, an integrated model for the development of sustainable assessment skills is presented. Finally, a research agenda is presented to further develop and test the presented model.

\section{What is sustainable assessment?}

This section gives an overview of the different types of assessment and compares summative assessment, formative assessment, and sustainable assessment with their original principles (see Table 1 for a schematic overview).

In this overview, the focus is on those aspects of summative and formative assessments that are relevant for explaining the main difference with sustainable assessment. The summative type of assessment focuses on the certification of achievement; grading and pass/fail decisions are the central focus. Summative assessment takes place after a learning phase and serves as assessment of learning (Sadler 1989). The teacher is typically responsible for student assessment and the student is a passive receiver of grades. Summative assessment is mostly criterion referenced, meaning that student performance is assessed on the basis of a list with pre-specified criteria (Sadler 2005; Sluijsmans, Straetmans, and Van Merriënboer 2008). In its original form, summative assessment gives judgements on these different performance criteria but provides no indication on how to improve performance. The students themselves have to take the responsibility to translate the assessment outcomes into points of improvement for future performance. Summative assessment has been in disarray for quite some time (see e.g. Knight 2002), because of 
Table 1. Schematic overview of developments in assessment practices.

\begin{tabular}{|c|c|c|c|}
\hline & $\begin{array}{l}\text { Summative } \\
\text { assessment }\end{array}$ & Formative assessment & Sustainable assessment \\
\hline Function & $\begin{array}{l}\text { Grading and } \\
\text { certification }\end{array}$ & To aid current learning & To aid lifelong learning \\
\hline \multirow[t]{2}{*}{$\begin{array}{l}\text { Role } \\
\text { division }\end{array}$} & $\begin{array}{l}\text { Teacher: gives } \\
\text { grades }\end{array}$ & Teacher: provides feedback & $\begin{array}{l}\text { Teacher: provides } \\
\text { feedback }\end{array}$ \\
\hline & $\begin{array}{l}\text { Student: } \\
\text { passively } \\
\text { receives grades }\end{array}$ & $\begin{array}{l}\text { Student: judges performance and } \\
\text { receives feedback }\end{array}$ & $\begin{array}{l}\text { Student: judges } \\
\text { performance and actively } \\
\text { judges feedback }\end{array}$ \\
\hline Criteria & $\begin{array}{l}\text { Using preset } \\
\text { criteria }\end{array}$ & Using preset criteria & $\begin{array}{l}\text { Developing a critical } \\
\text { attitude to criteria; using } \\
\text { both preset and newly } \\
\text { developed criteria }\end{array}$ \\
\hline Scope & $\begin{array}{l}\text { Past } \\
\text { performance }\end{array}$ & Current performance & Future performance \\
\hline $\begin{array}{l}\text { Main } \\
\text { points } \\
\text { of } \\
\text { critique }\end{array}$ & $\begin{array}{l}\text { Overemphasis } \\
\text { on grades; } \\
\text { process } \\
\text { blindness }\end{array}$ & $\begin{array}{l}\text { Focus insufficiently on (current) } \\
\text { learning; no separation of } \\
\text { feedback and grades; insufficient } \\
\text { use of self- and peer assessment }\end{array}$ & Unexplored \\
\hline
\end{tabular}

the negative effects on student learning. It may lead to an overemphasis on grades and learning outcomes and does not properly take the learning process into account. Whereas an important goal of assessment is the certification of students, summative assessment as such is not sufficient and may even be counterproductive to encourage effective learning. As in summative assessment, in formative assessment, prespecified criteria are normally used to assess student performance (Sluijsmans, Straetmans, and Van Merriënboer 2008). The results from a summative assessment can be used in a formative way if they are used to inform the students and give feedback on their progress (Dunn and Mulvenon 2009; Taras 2005).

The difference with summative assessment is that formative assessment focuses on the improvement of student performance. A key element is the provision of constant feedback to close the gap between current performance and desired performance, rather than the making of pass/fail decisions. Formative assessment takes place during the learning phase and has the goal of being assessment for learning (Sadler 1998). In an ideal form of formative assessment, the student has a central role in assessing his or her own performance (i.e. internal feedback) and in processing feedback given by peers and teachers (i.e. external feedback). Feedback is a key element in formative assessment and can be given formally as well as informally during learning (Sadler 1989). A comprehensive review study by Black and Wiliam (1998) revealed that formative assessment can lead to significant learning gains, but it also showed substantial weaknesses of assessment practices. The main problems are that the focus is often not on the learning process but on the performance, there is no clear separation of feedback and grading, and there is insufficient use of self-assessment and peer assessment, which are the core elements in teaching students to recognise learning gaps. In its original form, formative assessment is promising in theory but on its own, it is insufficient to help students learn to assess their own learning, and it does not prepare them to act as lifelong learners beyond graduation and throughout their entire career. 
As a reaction to the dissatisfaction with formative assessment practices, Boud (2000) introduced sustainable assessment as another type of assessment. Sustainable assessment helps students to become self-regulated learners as sustainable assessment skills help them in the process of planning, monitoring and controlling their own learning (Boekaerts, Pintrich, and Zeidner 2000). In order to define sustainable assessment, Boud builds on the principles of formative assessment described in the review by Black and Wiliam (1998). Whereas formative assessment typically focuses on making judgements to improve performance on the next learning task, sustainable assessment focuses not only on performance improvement, but also on improvement of the learning process in order to stimulate continuous learning beyond graduation. The main function of sustainable assessment is to teach students to self assess their own performance, so they can take responsibility for their own professional growth, as this is seen as a critical competence to enable lifelong learning (Tan 2008). To accomplish this, students judge their own performance not only on the level of single learning tasks but also over a series of tasks, that is, throughout the educational programme. The focus of summative and formative assessment is on current performance and learning, whereas sustainable assessment also explicitly focuses on future learning beyond graduation. Furthermore, the concept of sustainable assessment emphasises that students need to actively seek external assessments and feedback. Dealing with feedback and reactions to feedback are the frequently discussed topics in the formative assessment literature (e.g. Black and William 1998; Butler and Winne 1995; Carless 2007; Gibbs and Simpson 2004; Hattie and Timperley 2007; Shute 2008). Sustainable assessment goes further in demanding that students make conscious comparisons between self-assessments and assessments by teachers, peers and other stakeholders. The responsibility for the assessment process must gradually shift from the teacher to the students, because, after graduation, people themselves need to drive their own learning (Boud and Falchikov 2006; Nieweg 2004). Similar to summative and formative assessment, sustainable assessment is typically criterion-referenced, but above that, the concept of sustainable assessment stresses that students also have to develop a critical attitude towards criteria because when they enter the workplace, pre-specified criteria will not always be available to support them in judging their own performance and learning.

In conclusion, sustainable assessment builds on the principles of summative and formative assessment to help students becoming assessors of their own learning and consequently self-regulated learners. Although the emerging notion of sustainable assessment seems promising to better prepare students for the rapidly changing workplace, research is needed to explore how it can be applied in educational practice. In the next section, an integrated model for the development of sustainable assessment skills is introduced.

\section{The model}

Figure 1 presents the integrated model for developing sustainable assessment skills, including three main components: conditions for developing sustainable assessment skills, elements of sustainable assessment, and educational methods for guiding students in the development of sustainable assessment skills. The different components will be discussed in the following sections. 


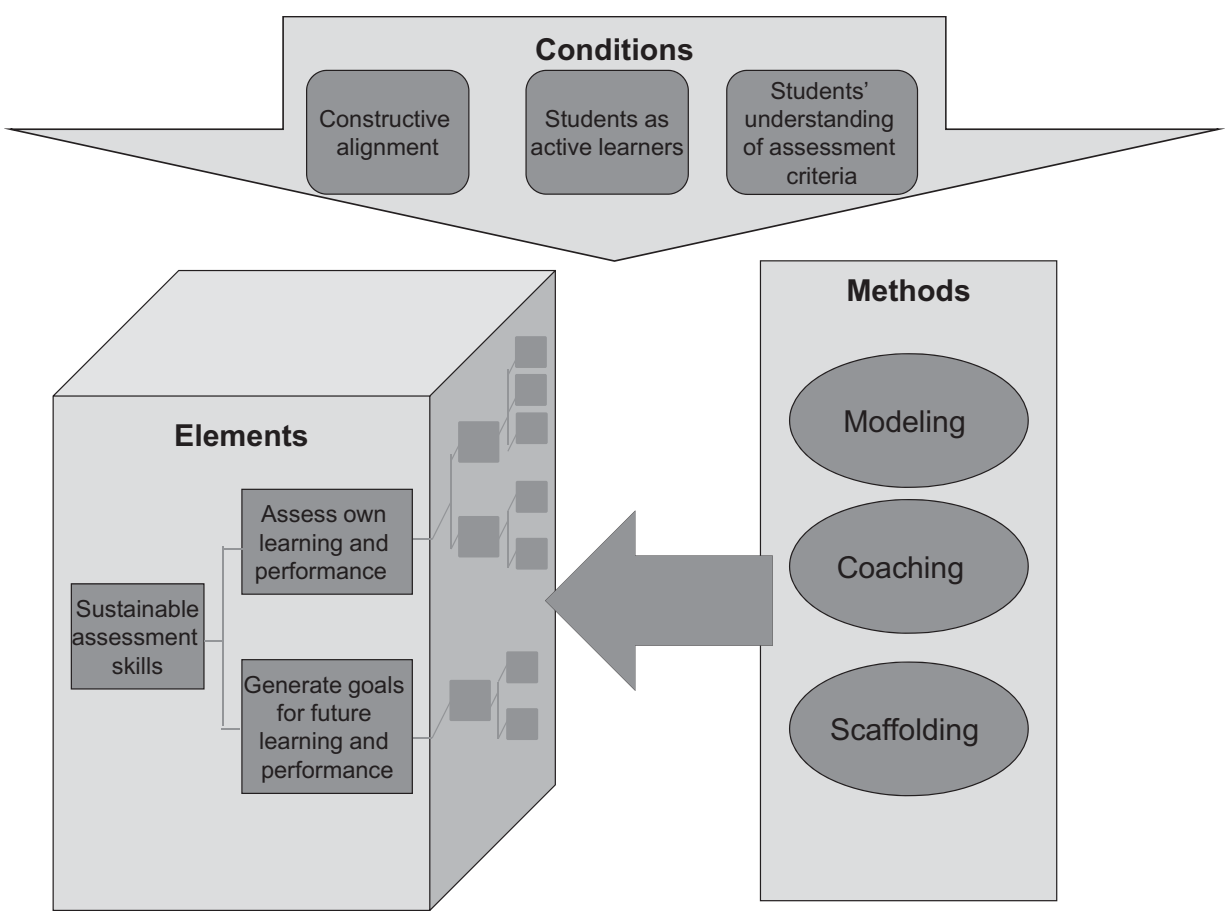

Figure 1. The integrated model for developing sustainable assessment skills.

\section{Conditions for developing sustainable assessment skills}

The first component of the model pertains to the conditions necessary for the development of sustainable assessment skills (upper part of the model). If the conditions are not met, sustainable assessment skills cannot be developed, irrespective of the educational methods used (Boud 2000; Boud and Falchikov 2007). All conditions that are important for formative assessment (e.g. the focus should be on learning rather than performance, reflective assessment with peers should be encouraged) also apply to sustainable assessment. However, for assessment to be sustainable, there are a number of additional conditions: constructive alignment, students as active learners and students' understanding of assessment criteria.

\section{Constructive alignment}

What will be assessed strongly influences what students learn. For example, if students must learn how to communicate with clients, communication skills have to be part of the assessment, if not, students will not be inclined to learn them. It is widely acknowledged that alignment between instruction and assessment is necessary in order to meet the goals of education (Biggs 1996). Nevertheless, in higher vocational education, assessment is often treated as an isolated element of the curriculum. Constructive alignment is most apparent in the self-directed learning cycle, where students go through a cyclical process of performing a task, assessing task performance, identifying points of improvement and planning future tasks (Van Merriënboer and Sluijsmans 2009). Then, assessment is the link that connects performance on one task to a plan for the following task (Ertmer and Newby 1996). It 
ensures that students receive relevant feedback that can be used as 'feed-forward' into future work (Carless 2007; Harris 2010). For example, when a student performs a learning task in which communication with the client is important, and it appears that his/her communication skills are not meeting pre-defined criteria, the student needs some additional practice and should select learning tasks that provide precisely this kind of practice.

Discontentment with the gap between higher vocational education and the workplace (Biemans et al. 2004) has encouraged educational institutions to implement learning tasks based on authentic, real-life situations in their vocational curricula. The fruitful use of authentic learning tasks presumes that assessment tasks also resemble real-life professional tasks, because competence-based education and competence-based assessment must go hand in hand (Dochy, Segers, and Sluijsmans 1999). This does not require assessments to take place in the workplace or in a genuine social context, but assessment tasks must resemble professional tasks to some degree and the learning they measure should have clear value beyond the classroom (Gulikers, Bastiaens, and Kirschner 2004; Kerka 1995). During their higher education, students must show that they are ready to enter professional practice. For example, a student nurse has to show acceptable performance of nursing tasks with simulated and then real patients, meeting preset performance criteria, before being allowed to enter the labour market.

Boud and Falchikov (2006) advocate that constructive alignment within the programme of study is necessary but not sufficient for assessment to be sustainable; alignment with long-term purposes is also of paramount importance. In higher vocational education, students should develop the skills necessary to recognise their future learning needs, and there should be alignment of assessment practices with these future needs (Kicken et al. 2009a). For example, when a new technique is introduced in nursing, qualified nurses should be able to establish their own way of learning to become familiar with this new technique. By integrating an orientation on the future in their programmes of study, students get used to this way of thinking, which helps them to become more future oriented in their careers.

\section{Students as active learners}

Feedback on performance should be aimed at reducing the discrepancy between current and desired performance. It should address three important questions students should constantly be aware of: (1) Where are you going? (2) How are you going? (3) Where to go next? (Harris 2010; Hattie and Timperley 2007). Students must learn to interpret external feedback from teachers, peers or others to determine possible gaps between their actual performance and desired performance (i.e. performance criteria) and to identify points of improvement. In order to critically consider received feedback, a safe learning environment is required (Govaerts et al. 2007). Whatever the feedback is about (e.g. performance, learning or person-related), it is important that the classroom climate is open so that external feedback can be welcomed and used by students (Liu and Carless 2006). In this climate, there has to be ample room for making errors, and feedback should primarily be seen as an instrument for improving performance. The teacher has an important role in formulating the feedback and creating a safe learning environment.

However, after graduation, it is neither the teacher nor the curriculum but the learners who drive their own learning (Blair 2005; Nieweg 2004). So, if students 
only rely on feedback from others, they will never acquire the skills necessary to judge their own performance or to do their own work competently (Boud and Falchikov 2006). Therefore, they must be actively involved in the practice of making informed judgements as part of the curriculum. This may be accomplished through peer assessment and self-assessment, which helps students to gain expertise in the evaluation of task performance (Sadler 1989, 2010). Whereas peer assessment helps students to learn how to formulate feedback on the difference between observed performance and performance criteria, self-assessment eventually enables them to learn how to formulate internal feedback about the difference between their own performance and the criteria. The teacher has to coach the students in acquiring these skills.

Finally, in their future careers, graduates will encounter situations in which they receive conflicting external feedback from different parties, or feedback that conflicts with their own ideas. Because external feedback can augment, concur or conflict with internal feedback, students need to develop the ability to cope with the discrepancies between external and internal feedback in order to support their learning (Nicol and Macfarlane-Dick 2006). For assessment to be sustainable, students need to consciously compare feedback from external parties with their self-assessments (e.g. as part of 360-degree feedback; Brett and Atwater 2001) to obtain an accurate view of their performance and to learn to conduct better self-assessments. For example, a student nurse receives feedback from peers, teachers, senior nurses and patients during an internship, and the student has to compare that feedback with his own internal feedback and identify discrepancies and possible explanations for these discrepancies. This process will help to clarify performance criteria and to improve the formulation of points-of-improvement.

\section{Students' understanding of assessment criteria}

When students are not familiar with the performance criteria that determine whether or not their performance is of acceptable quality, they may not self assess their performance well and, even worse, they may not perform well. Consequently, they may try to improve their performance by trial-and-error rather than by trying to close the gap with the criteria (Sadler 1989). For example, if a student nurse is not aware of the importance of communicating with patients, the student may not understand why a patient is feeling uncomfortable when given an intravenous injection. In reaction to this, the student nurse might use a different needle next time rather than comforting the patient by a conversation.

Transparent performance criteria can lead to better performance and selfassessments of students (Sadler 2009). But for assessment to be sustainable, students should not only be able to deal with preset performance criteria, but also learn to actively seek and formulate these criteria themselves and determine which criteria are important in judging their work, because in their future workplaces they will usually not be provided with lists of relevant criteria (Boud 2000). For example, when a car mechanics student has to fix a certain engine problem for the first time, the student has to consider which particular criteria are important for that particular type of engine and that particular type of problem. Teachers can encourage the process of understanding assessment criteria by a series of processes ranging from prescribing the criteria, to negotiating the criteria together with the students, to requiring the students to develop their own criteria in a later study stage (Sadler 2009). 
Concluding this section, there are three conditions for the development of sustainable assessment skills; there is constructive alignment between instruction and assessment; students are active participants in the learning process, and students understand the assessment criteria. The next sections take a closer look at sustainable assessment skills and their development.

\section{Elements of sustainable assessment}

The second component is represented on the left part of the integrated model for developing sustainable assessment skills (see left part of the model in Figure 1). It pertains to the analysis of the elements of sustainable assessment. It should be noted that the teacher has a crucial role in helping students develop sustainable assessment skills. This is described in the section about the methods for guiding students in developing sustainable assessment skills. In the current section, the ideal situation is described, being the end result of the study programme. If students are supposed to develop sustainable assessment skills, the curriculum has to pay attention to the development of both self-assessment and goal-setting skills. These are the two constituent parts on the second level of a so-called skills hierarchy (Van Merriënboer 1997). Based on the literature that will be discussed below, Figure 2 shows a more detailed hierarchy of sustainable assessment skills.

\section{Self assessment of performance and learning}

In order to become skilled in sustainable assessment, students must learn to assess their own performance on both single tasks (How well do I perform?) and over a series of tasks (Does my performance improve over tasks?). Performance over tasks may either increase, stay the same or decrease, thereby indicating learning or a lack

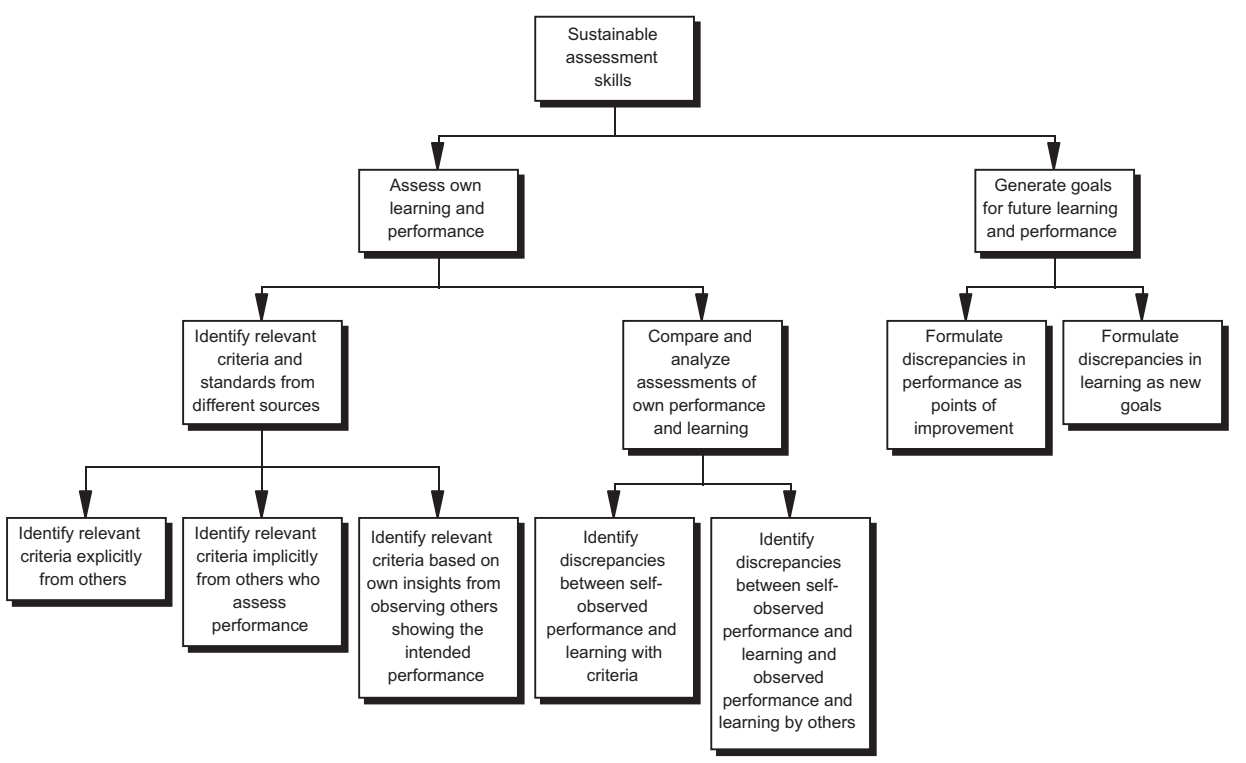

Figure 2. Skills hierarchy of sustainable assessment skills. 
of learning. Assessment of one's own performance and learning requires (a) skills to identify relevant criteria for assessment from different sources (Boud 1995) and (b) skills to critically compare and analyse different assessments of one's own performance and/or learning (see left part of the hierarchy in Figure 2). These are the constituent parts of the third level in this figure. Concerning performance (i.e. within one task), students judge whether the identified criteria are reached for a particular task; concerning learning (i.e. over different tasks), students judge if there is sufficient improvement of performance in the direction of the identified criteria.

Going one step further down in the hierarchy (see bottom left part of Figure 2), three parts constitute the ability to identify relevant criteria for performance and learning. Students must learn to identify criteria explicitly provided by others, implicitly used by others who assess their performance and implicitly used by others who demonstrate intended performance.

After graduation, people are usually not given preset, explicit criteria. However in educational settings, students often receive explicit assessment criteria (Tan 2007). For example, when a student nurse for the first time enters a nursing home in which patients with dementia are treated, the student has to identify the relevant criteria for effective communication with this group of patients. Such criteria can be made explicit by a teacher, instructional materials, an internship supervisor or a peer student. They are mostly formulated on the level of task performance. For students, it is important to fully understand and learn to interpret the criteria that are explicitly provided to them, and then use these criteria to monitor if their performance over tasks is moving towards the criteria, i.e. if sufficient learning over tasks is taking place.

Next to that, students must learn to identify the criteria, implicitly applied by others that assess their performance or learning. Teachers, peers and relevant others (e.g. clients) all use individual implicit criteria in assessing student performance, and it is important for students to (try to) identify these criteria and invite different stakeholders to explain them in order to learn to identify the relevant criteria. For example, a student nurse can ask the patients how they like to be treated, so the student knows what the patients expect; that is, which criteria are applied by the patients. Implicit criteria from others can be related not only to particular tasks but also to performance improvement over tasks. For example, a supervisor may apply specific criteria for monitoring the learning process and expect a certain degree of growth over learning tasks without explicitly stating these expectations. In such cases, it is important for students to possess the necessary skills to stimulate assessors to make their criteria explicit.

Furthermore, students must learn to use others' observations of their performance to generate criteria. This is closely related to modelling, where students imitate experts or teachers who show the required performance. But this process is complex and often needs instructional support and guidance (O'Donovan, Price, and Rust 2004), because learners need to move away from concrete performances and use their insights to deduce the performance criteria used by experienced task performers. For example, when students observe a supervisor or senior colleague demonstrating required performance, they should be able to deduce the important criteria from the observed performance.

One level up in the hierarchy, as a second component of assessing own learning and performance, it is indicated that students must be able to compare and analyse different assessments (i.e. self-assessments and assessments by others) to properly 
assess their performance and learning (see Figure 2). In order to do so, they should be able to identify discrepancies between their own performance and learning and previously identified criteria, and between self-assessments of their performance and learning, and assessments of their performance and learning by others. In analysing discrepancies between their own performance and learning and the assessment criteria, students have to look at their own performance and learning and critically compare it with criteria identified from different sources. By doing so, they learn to form judgements of their own performance and learning, that is, they develop selfassessment skills (Boud 2007). These self-assessment skills are the basis for the next step of comparing self-assessments with assessments by others.

With regard to analysis of discrepancies between self-assessments (internal information) and assessments by others (external information from teachers, peers, clients and so forth), assessments by others may be consistent or conflicting with each other and also with students' self-assessments (Paris and Paris 2001; Sergeant et al. 2008). Then, the student has to combine these conflicting views. For example, a car mechanics student may think that the verbal communication with the clients is going well, while a senior car mechanic may come to an opposite assessment. A considerable number of studies have addressed students' reactions to external feedback (Black and Wiliam 1998; Butler and Winne 1995; Hattie and Timperley 2007; Mory 2003; Kluger and DeNisi 1996). For sustainable assessment, it is important that students actively process and use the feedback they receive from other parties, and also compare it critically with their own assessments of performance and learning (Boud 2000; Nicol and Macfarlane-Dick 2006). The car mechanics student must acknowledge the feedback from the senior car mechanic and reflect on his/her own task performance to examine whether the feedback is understood. Recent studies by Eva and Regehr (2008) and Sergeant et al. (2008) confirm this idea, introducing new terms such as 'self-directed assessment seeking' and 'informed self-assessment', and stressing that students must learn to compare external assessments and self-assessments in a reflective process in order to develop sustainable assessment skills.

\section{Generation of goals for future performance and learning}

Based on a profound assessment of their actual performance and its development over tasks, students have to generate goals for future performance and plan their learning to reach these goals (see branch on the right in Figure 2). The two constituent parts lower in the hierarchy indicate that students must be able to formulate identified discrepancies between actual and desired performance as points of improvement, and set new goals for learning (Butler and Winne 1995).

The formulation of points of improvement is based on discrepancies identified earlier by comparing the students' own viewpoints and the feedback provided by others (Ertmer and Newby 1996), and should be done at a specific and observable level so that students know precisely what to work on. This will help them focus their attention on weak aspects of their performance in future tasks, or alternatively, select subsequent learning tasks that are best suited to work on the identified points of improvement (Kicken et al. 2009a). For example, the student nurse who wants to improve his communication skills with patients with dementia first has to formulate concrete and specific points of improvement (e.g. 'always ask for confirmation to 
check whether the patient understands me' rather than 'improve my communication skills') and then has to work on improving exactly those aspects of the skill in subsequent tasks.

Apart from being able to formulate points of improvement, students should learn to set new learning goals. As stated earlier, graduates have to be able to drive their own learning and set their own goals. Formulating learning goals is an important step in deciding what to learn and how to work towards that goal. When students have diagnosed their learning needs by exploring discrepancies, they must formulate goals and decide which learning activities can help them to fulfil these goals (Ertmer and Newby 1996; Knowles 1975; Loyens, Magda, and Rikers 2008). As advocated by Eva and Regehr (2005), goals should be appropriately challenging based on earlier assessments, and for this reason, earlier assessments must also be a realistic representation of students' performance levels.

\section{Methods for guiding students in developing sustainable assessment skills}

The previous sections discussed, in order, the conditions for the development of sustainable assessment skills, and the constituent parts of these skills. This section discusses the third component of the model (see right part of Figure 1), giving an overview of how students can best be guided in the development of sustainable assessment skills.

By definition, a novice in a domain may be unable to make refined judgements about high-quality performance in that domain (Sadler 1989). In the beginning of their study, students are not able to fulfil all assessment duties themselves. It is therefore important that during a study programme, as domain expertise increases, assessment responsibilities are gradually handed over from the teacher to the students by providing them with authentic but increasingly less guided assessment experiences. The cognitive apprenticeship model originally proposed by Brown, Collins, and Duguid (1989) states that learning complex cognitive skills has to take place in authentic contexts for the learned skills to transfer outside the learning setting. The cognitive apprenticeship model presents three methods to accomplish the gradual shift of responsibilities from teacher to students: modelling, coaching and scaffolding. First, these methods will be discussed in general, and in the following sections, these methods will be applied to the development of sustainable assessment skills.

Modelling indicates that students observe the task performance of experts to learn what good performance is (i.e. performance that meets relevant criteria). Coaching indicates that observation of student performance is always followed by the provision of informative feedback, aimed at the improvement of students' task performance. Scaffolding indicates that teacher support gradually diminishes until students are able to perform the tasks independently. Together, these methods are expected to offer students the necessary guidance for developing sustainable assessment skills. The teacher has a crucial role in guiding students through this process. Table 2 links the two main skills for sustainable assessment, self-assessment of performance and learning and generating goals for future performance and learning, to the methods of modelling, coaching and scaffolding. The methods will be discussed in more detail below. 


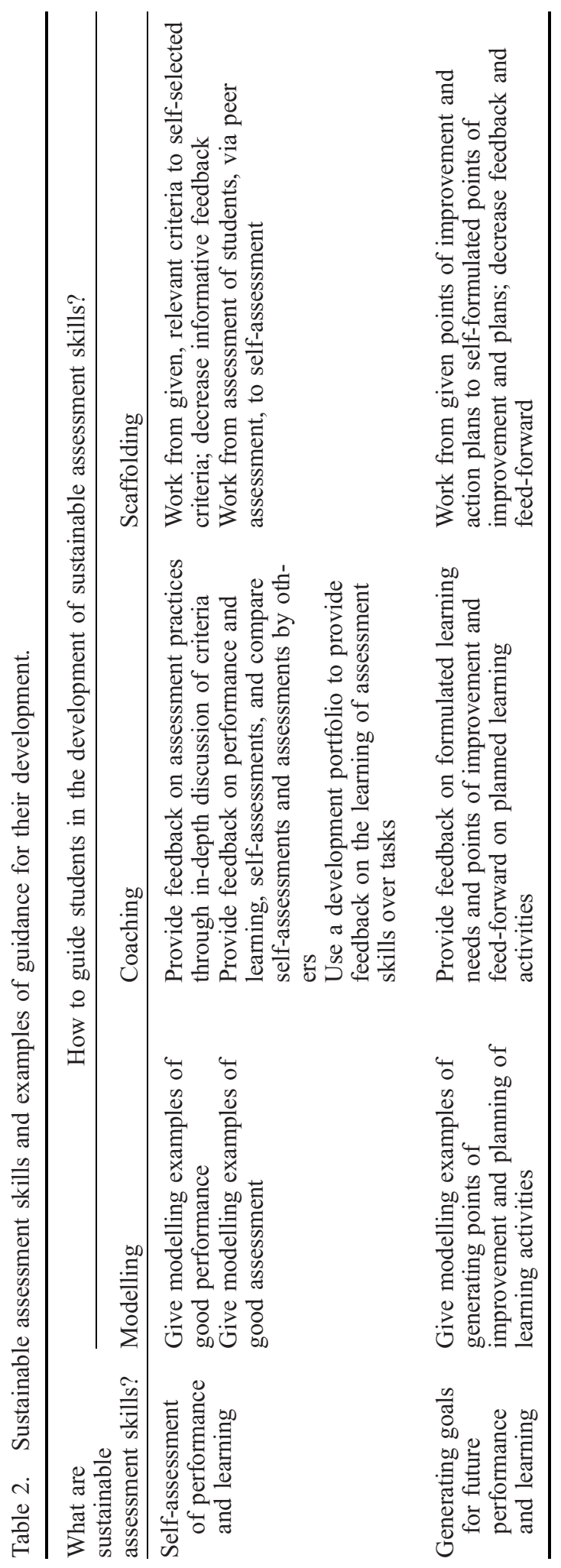




\section{Self-assessment of performance and learning}

When graduates enter the workplace, they must possess skills to identify relevant performance criteria and skills to compare and analyse different assessments of their performance and learning. These skills are essential for successful lifelong learners (Boud and Falchikov 2007), and will be discussed separately.

With regard to the identification of relevant performance criteria, it is not useful to ask students to do this right from the beginning of a study programme, because it can easily lead students to focus on aspects that are irrelevant for the task at hand (Orsmond, Merry, and Reiling 2002). If students need to learn to identify relevant criteria, teachers should gradually hand over this task to their students.

A possible activity in teaching students to identify relevant criteria is to provide them with examples of expert performance. These examples can take the form of modelling examples which demonstrate excellent performance to students (Harris 2010; Van Merriënboer, Jelsma, and Paas 1992). In order to be effective, these examples need to offer insight into the end result and into the entire process of reaching it. That is, the examples should be process oriented and explain why particular performances yield desired results (Van Gog, Paas, and Van Merriënboer 2008). Orsmond, Merry, and Reiling (2002) found in an empirical study with firstyear Environmental Sciences and Applied Biology undergraduates that the use of exemplars in producing a poster helped students to understand the marking criteria and standards, led to higher learning outcomes, and helped to provide meaningful feedback. However, the exemplars used in this study were only final products and were not process oriented. An example of a process-oriented exemplar is to show the student how to produce the poster from scratch to end product with an explanation of each step taken. Future research is necessary to provide further empirical support for the effects of process-oriented worked examples.

Coaching can be used to teach students to identify relevant criteria by giving them feedback on the criteria they use. After they have been shown clear definitions of criteria along with illustrative examples as described above, students should be given the opportunity to acquire the skills for properly using the criteria. This can be achieved by offering assessment exercises where students use the presented criteria to judge other students' work and/or their own work (Nicol and MacfarlaneDick 2006). The use of peer assessment has an important function, because it gives students appraisal experience that is similar to the teacher's (Sadler 2010). This can be useful for deriving the criteria as the work of peers should be assessed with the same criteria as their own work. An alternative is described by Rust, Price, and O'Donovan (2003), who demonstrated (in an empirical study with business students) the effectiveness of discussions between students and teachers about the criteria of good work, which improved their performance but not their self-assessment skills (see also Nicol and Macfarlane-Dick 2006). The findings of Orsmond, Merry, and Reiling (2000) revealed that a discussion between students and teachers may lead to a more positive appreciation of the criteria, but not to a better understanding of the criteria as such or the ability to actually use them for the assessment of performance. So far, research results do not allow for univocal conclusions and more research on how to provide effective feedback on the identification of criteria is needed.

To scaffold the skill of identifying relevant criteria, the available support is reduced. Early in the learning process, students should receive sufficient practice 
with given, relevant criteria to fine-tune the skill of identifying relevant criteria (Sadler 1989). Practice must be supplemented by discussion and dialogue to provide informative feedback on the setting and use of criteria. Later on in the learning process, students must independently select criteria that are relevant for particular tasks from all available criteria and the provision of feedback on applied criteria gradually diminishes as the curriculum moves forward.

Modelling, coaching and scaffolding are also useful methods to guide students in the development of their skills in analysing and comparing self-assessments of their performance and learning. Modelling examples of well-conducted assessments can be offered where the teacher or an expert acts as a model when assessing task performance (Van Merriënboer and Sluijsmans 2009). Modelling examples encourage students to develop ideas of how good assessment is performed. In this process, it is necessary that teachers clearly describe the steps they take in conducting the assessment, and also explain why they take these particular steps (i.e. processoriented modelling examples), so that students gain insight into the assessment process and the relevant considerations for reaching a particular judgement. To date, we have found no evidence of research that has dealt with this type of modelling assessments.

Next to that, teachers and peers can coach by providing feedback against which students can evaluate self-assessments of their performance (Nicol and MacfarlaneDick 2006). Taras (2003) demonstrated in an empirical study that Specialist Language students indeed learn most from self-assessments when they are combined with tutor feedback, because this helps students to be aware of all their errors. Tutor feedback should not be limited to external feedback on students' performance and learning; feedback should also be provided on the quality of self-assessments (Ertmer and Newby 1996; Hattie and Timperley 2007) and the process of comparing and analysing internal feedback (self-assessments) with external feedback (assessments from others). Reflective dialogue with students will help them to make optimal use of the feedback (Nicol and Macfarlane-Dick 2006). It helps them to make better use of external feedback, to make better comparisons between internal and external feedback, and, eventually, to become better self-assessors (Taras 2003). A development portfolio can be used to collect all received feedbacks (internal and external) and can make it easier for students to assess their learning over a series of tasks (Harris 2010; Tillema et al. 2000). A coach or supervisor can help students to interpret the results of the different assessments in the portfolio and guide the future learning process as is shown in a study with medical students (Driessen et al. 2005).

After that, students can be guided in self assessing their performance and learning by reducing support. This involves giving students increasingly more control over their learning process (Corbalan, Kester, and Van Merriënboer 2008). An important condition is that students must be made aware that they are not just temporary learners, but active and future lifelong learners who must take over responsibility from their teachers (Boud and Falchikov 2007). A gradual shift of responsibility from teacher to student has to take place, for example, from assessing student performance, to asking students to assess the performance of peers, to asking students to self assess their own performance. As indicated before, peer assessment is a powerful intermediate stage to support students in gaining self-assessment skills, because the work of fellow students is easily accessible and of the same type as their own work (Sluijsmans et al. 2004). It is less threatening for students to assess other 
students' work than their own (Sadler 1989; Van Gennip, Segers, and Tillema 2009), and the skills for peer assessment and self-assessment are comparable (Liu and Carless 2006). It is therefore important to help students to understand how they can learn from each other (Harris 2010). In addition, students can also learn from comparing their own assessments with the assessments they receive from their peers. As Van Gennip, Segers, and Tillema (2009) describe in their review study, several conditions are necessary to enable students to work on their peer assessment skills. This relates to interpersonal features such as psychological safety and trust, and to structural features such as peer interaction and group composition. However, more research is needed to explore these features in detail.

\section{Generation of goals for future performance and learning}

Most students are not used to explicitly formulating or thinking about their learning needs (Holme and Chalauisaeng 2006). The ability to formulate learning goals presupposes the ability to formulate learning needs (i.e. discrepancies between actual and desired performance), related points of improvement and learning activities. Therefore, it is important that students are explicitly encouraged to think about ways of improving their own performance without possibly negative consequences for their results. The skills of generating goals of future performance and future learning will be discussed separately.

The use of modelling examples helps students to develop the skill of formulating points of improvement. This can be done by a teacher or coach who demonstrates the interpretation of assessment results and the formulation of points of improvement as is shown in a study by Kicken et al. (2009b). In their research in a hairdressing training programme, they used a development portfolio which, besides a self-assessment instrument, focused on the formulation of points of improvement and task selection aspects. They showed that with the necessary teacher support and advice, a development portfolio leads to the formulation of better points of improvement.

Above that, teachers or supervisors can coach students by giving feedback on the points of improvement that students have formulated themselves. Once students are aware of the real causes of their shortcomings, they are better able to formulate points of improvement. Assessors can also formulate points of improvement - or students can ask them to do so - enabling students to compare and contrast their own points of improvement with those suggested by others (Kicken et al. 2009b).

As students gain more experience in formulating points of improvement, the support provided by the teacher or coach should diminish. For example, first the teacher may formulate points of improvement for a particular student based on available assessment results, then the student may formulate points of improvement with feedback from the teacher on these points of improvement, and finally the student formulates the points of improvement without any support. To date, we have found no evidence of research that has shed light on this diminishing amount of support in formulating points of improvement.

Modelling examples can also be used for formulating new learning goals over several learning tasks. According to Kicken et al. (2009b), this can be done by a teacher or coach who explains why particular learning activities are chosen to meet the identified goals, based on the points of improvement. In the same study, it appeared that when students got advice in combination with a development portfolio, they were better able to choose future learning activities to work on. 
Students should also be given feedback by their teachers or supervisors on the learning goals they formulate based on the points of improvement they formulated earlier. In addition, coaching should not be limited to feedback, in which students look back with their teachers to explore weaknesses and the causes thereof, but also include feed-forward, in which advice is given on future learning activities to resolve the weaknesses. Detailed points of improvement make it easier to identify relevant learning activities as was shown in the research of Kicken et al. (2009b). Feedback and feed-forward may pertain to both the level of single-task performance and the level of multiple-task learning. Together with a coach or supervisor, students can look at their learning progress as documented in a development portfolio and formulate learning needs, points of improvement and new learning activities based on that overview (Driessen et al. 2005).

When students become more familiar with planning, future learning activities and setting new learning goals, the support provided by the teacher should diminish. For example, first, the teacher may formulate future learning activities for a particular student based on the points of improvement formulated earlier, then the student may formulate new learning goals with support of the teacher or coach, and finally the student plans his or her future learning activities independently. To date, we have found no evidence of research that has shed light on how to diminish the amount of support in planning future learning activities and setting new learning goals.

\section{Discussion}

This article discussed an integrated model for the development of sustainable assessment skills. We first compared the features of sustainable assessment with the features of summative and formative assessment. Past research offered valuable insights into organising effective and efficient summative and formative assessments, but our knowledge regarding the use of sustainable assessment is still in its infancy.

The proposed model describes an ideal situation and consists of three components: conditions that must be fulfilled for sustainable assessment skills to develop, elements of sustainable assessment and methods for the development of sustainable assessment skills. As for conditions, there must be constructive alignment between instruction and sustainable assessment; students should be active learners, and students must understand the assessment criteria. With regard to the elements of sustainable assessment, the skill to self assess performance and learning, the skill to generate goals for future performance and learning, and several lower-level enabling skills were identified. With regard to methods for teaching sustainable assessment skills, cognitive apprenticeship and its related methods of modelling, coaching and scaffolding offer valuable suggestions for instruction.

Since this model is an attempt at providing a framework for the concept of sustainable assessment and its development, some critical remarks should be made. First, the presented model is based on a literature review including more conceptual than empirical papers, making it impossible to draw definite conclusions. Further empirical research is needed to test whether the proposed model needs adaptations and/or extensions. It is likely that future research will increase our understanding of additional conditions that need to be fulfilled and will provide more detailed insights that can be included in the skills hierarchy. For example, additional conditions may pertain to the use of tools (e.g. portfolios) or the training of teachers in guiding students, and the planning of future learning may 
need a more detailed description of the skills hierarchy. The cognitive apprenticeship model of Brown, Collins, and Duguid (1989) was taken as a sound starting point for the description of methods to guide students in their development of sustainable assessment skills, but possibly other models can be used to come up with alternative methods.

There are some important research implications that can be derived from the model. Future research might focus on the provision of high-standard exemplars in the form of modelling examples, where teachers demonstrate how to perform according to relevant criteria, how to assess on the basis of these criteria and how to formulate points of improvement and plan future learning. Process-oriented examples pay explicit attention to why particular actions are taken, and their use could be coupled with research on the effects of group discussions with students. Furthermore, future research might focus on the effects of feedback and coaching on the different elements of sustainable assessment, including the correct and incorrect use of performance criteria, the quality of self-assessments, the comparisons of self-assessments and assessments by others, the formulation of learning needs and points of improvement, and the formulation of new learning goals. Special attention could be devoted to the role of development portfolios in providing feedback on the development of sustainable assessment skills over a series of tasks, specifically, on the development of assessment skills throughout the educational programme. Additionally, more research is needed to clarify how scaffolding of all sustainable assessment skills can best be organised.

A practical implication that follows from the model is that teachers and policy-makers in higher vocational education should consider the development of sustainable assessment skills as a valuable goal of educational programmes. They should ensure that the conditions for the development of sustainable assessment skills are met, and also stimulate educational innovations that aim to develop sustainable assessment skills. Some of the methods discussed in this article have already been proven to work in educational practice and could be implemented in educational institutions. For example, the research of Kicken et al. (2009b) showed that the use of a development portfolio in combination with regular coaching settings can help students to make more use of assessments, plan their future learning more deliberately and gain more insight into their learning process.

In conclusion, sustainable assessment can be regarded as a promising idea to help students to become lifelong learners, but further development is needed to determine how sustainable assessment skills can best be taught. This article offered some starting points for a theoretical foundation of sustainable assessment and gave suggestions for future research on this topic. It is noteworthy to mention that such research should not be restricted to the education sector but also needs to include graduates' workplace learning. Only then it will become clear if the guidelines proposed in this article can actually contribute to the development and application of sustainable assessment skills.

\section{Notes on contributors}

Greet M. J. Fastré combines her work as a research coordinator of the Limburg Catholic University College and a teacher educator at the University of Hasselt. She specializes in assessment with a focus on self-assessment and sustainable assessment. 
Marcel R. van der Klink combines his work as a research director of the research group Innovation \& Professional Development of Zuyd, University of Applied Science with a job position as an associate professor at the Open University of the Netherlands. He specializes in workplace learning, competence-based education, professional development and elearning.

Dominique Sluijsmans works as an associate professor at HAN University, where she leads several projects on sustainable assessment. She specializes in assessment with a focus on peer assessment and sustainable assessment.

Jeroen J. G. van Merrienboer is a full professor of Learning and Instruction at the Graduate School of Health Professions Education at Maastricht University, the Netherlands. He specializes in instructional design, complex learning and the use of ICT in education. He has published over 100 articles on these topics.

\section{References}

Biemans, H., L. Nieuwenhuis, R. Poell, M. Mulder, and R. Wesselink. 2004. Competencebased VET in the Netherlands: Background and pitfalls. Journal of Vocational Education and Training 56: 523-38.

Biggs, J. 1996. Enhancing teaching through constructive alignment. Higher Education 32: 347-64.

Black, P., and D. Wiliam. 1998. Assessment and classroom learning. Assessment in Education: Principles, Policy and Practice 5: 7-74.

Blair, M. 2005. Accrediting lifeplace learning (including work-based and work place learning) as part of the Scottish Higher Education Curriculum. Doctoral Thesis, Glasgow Caledonian University.

Boekaerts, M., and P.R. Pintrich, and M. Zeidner, eds. 2000. Handbook of self-regulation. San Diego, CA: Academic Press.

Boud, D. 1995. Enhancing learning through self-assessment. London: Kogan Page.

Boud, D. 2000. Sustainable assessment: Rethinking assessment for the learning society. Studies in Continuing Education 22: 151-67.

Boud, D. 2007. Reframing assessment as if learning were important. In Rethinking assessment in higher education: Learning for the longer term, ed. D. Boud and N. Falchikov, 14-25. New York, NY: Routledge.

Boud, D., and N. Falchikov. 2006. Aligning assessment with long-term learning. Assessment and Evaluation in Higher Education 31: 399-413.

Boud, D., and N. Falchikov. 2007. Developing assessment for informing judgement. In Rethinking assessment in higher education: Learning for the longer term, ed. D. Boud and N. Falchikov, 181-97. New York, NY: Routledge.

Brett, J.F., and L. Atwater. 2001. 360 feedback: Accuracy, reactions, and perceptions of usefulness. Journal of Applied Psychology 86: 930-42.

Brown, J.S., A. Collins, and P. Duguid. 1989. Situated cognition and the culture of learning. Educational Researcher 18: 32-42.

Butler, D.L., and P.H. Winne. 1995. Feedback and self-regulated learning: A theoretical synthesis. Review of Educational Research 65: 245-81.

Carless, D. 2007. Learning-oriented assessment: Conceptual bases and practical implications. Innovations in Education and Teaching International 44: 57-66.

Corbalan, G., L. Kester, and J.J.G. Van Merriënboer. 2008. Selecting learning tasks: Effects of adaptation and shared control on learning efficiency and task involvement. Contemporary Educational Psychology 33: 733-56.

Dochy, F., M. Segers, and D. Sluijsmans. 1999. The use of self-, peer and co-assessment in higher education: A review. Studies in Higher Education 24: 331-50.

Driessen, E.W., J. Van Tartwijk, K. Overeem, J.D. Vermunt, and C.P.M. Van der Vleuten. 2005. Conditions for successful reflective use of portfolios in undergraduate medical education. Medical Education 39: 1230-5. 
Dunn, K.E., and S.W. Mulvenon. 2009. A critical review of research on formative assessments: The limited scientific evidence of the impact of formative assessments in education. Practical Assessment, Research, and Evaluation 14. http://pareonline.net/genpare. asp?wh=0andabt=14 (accessed July 6, 2010).

Ertmer, P.A., and T.J. Newby. 1996. The expert learner: Strategic, self-regulated, and reflective. Instructional Science 24: 1-24.

Eva, K.W., and G. Regehr. 2005. Self-assessment in the health professions: A reformulation and research agenda. Academic Medicine 80: S46-54.

Eva, K.W., and G. Regehr. 2008. 'I'll never play professional football' and other fallacies of self-assessment. The Journal of Continuing Education in the Health Professions 28: $14-9$.

Gibbs, G., and C. Simpson. 2004. Conditions under which assessment supports student learning. Learning and Teaching in Higher Education 1: 3-31.

Govaerts, M.J.B., C.P.M. Van der Vleuten, L.W.T. Schuwirth, and A.M.M. Muijtjens. 2007. Broadening perspectives on clinical performance assessment: Rethinking the nature of in-training assessment. Advances in Health Sciences Education 12: 239-60.

Gulikers, J., T. Bastiaens, and P.A. Kirschner. 2004. A five-dimensional framework for authentic assessment. Educational Technology Research and Development 52: 67-85.

Harris, M. 2010. Little things that make the difference. QAA Enhancement Themes Web Site. $1-27$.

Hattie, J., and H. Timperley. 2007. The power of feedback. Review of Educational Research 77: $81-112$.

Holme, R., and B. Chalauisaeng. 2006. The learner as needs analyst: The use of participatory appraisal in the EAP reading classroom. English for Specific Purposes 25: 403-19.

Kerka, S. 1995. Techniques for authentic assessment: Practice application brief. Columbus: ERIC Clearinghouse on Adult, Career, and Vocational Education.

Kicken, W., S. Brand-Gruwel, J.J.G. Van Merrienboer, and W. Slot. 2009a. Design and evaluation of a development portfolio: How to improve students' self-directed learning skills. Instructional Science 37: 453-73.

Kicken, W., S. Brand-Gruwel, J.J.G. Van Merriënboer, and W. Slot. 2009b. The effects of portfolio-based advice on the development of self-directed learning skills in secondary vocational education. Educational Technology Research and Development 57: 439-60.

Kluger, A.N., and A. DeNisi. 1996. The effects of feedback interventions on performance: Historical review, a meta-analysis and a preliminary feedback intervention theory. Psychological Bulletin 119: 254-84.

Knight, P.T. 2002. Summative assessment in higher education: Practices in disarray. Studies in Higher Education 27: 175-286.

Knowles, M. 1975. Self-directed learning: A guide for learners and teachers. Englewood Cliffs, NJ: Prentice Hall/Cambridge.

Liu, N., and D. Carless. 2006. Peer feedback: The learning element of peer assessment. Teaching in Higher Education 11: 279-90.

Loyens, S.M.M., J. Magda, and R.M.J.P. Rikers. 2008. Self-directed learning in problembased learning and its relationships with self-regulated learning. Educational Psychology Review 20: 411-27.

McDonald, R., D. Boud, J. Francis, and A. Gonczi. 1995. New perspectives on assessment, 45. Paris: UNESCO.

Mory, E.H. 2003. Feedback research revisited. In Handbook of research on educational communications and technology, ed. D.H. Jonassen, 745-83. New York, NY: MacMillian.

Nicol, D.J., and D. Macfarlane-Dick. 2006. Formative assessment and self-regulated learning: A model and seven principles of good feedback practice. Studies in Higher Education 31: 199-218.

Nieweg, M.R. 2004. Case study: Innovative assessment and curriculum redesign. Assessment and Evaluation in Higher Education 29: 203-14.

O'Donovan, B., M. Price, and C. Rust. 2004. Know what I mean? Enhancing student understanding of assessment standards and criteria. Teaching in Higher Education 9: 325-35.

Orsmond, P., S. Merry, and K. Reiling. 2000. The use of student derived marking criteria in peer and self-assessment. Assessment and Evaluation in Higher Education 25: 23-38. 
Orsmond, P., S. Merry, and K. Reiling. 2002. The use of exemplars and formative feedback when using student derived marking criteria in peer and self-assessment. Assessment and Evaluation in Higher Education 27: 309-23.

Paris, S.G., and A.H. Paris. 2001. Classroom applications of research on self-regulated learning. Educational Psychologist 36: 89-101.

Regehr, G., and K.W. Eva. 2006. Self-assessment, self-direction and the self-regulating professional. Clinical Orthopaedics and Related Research 449: 34-8.

Rust, C., M. Price, and B. O'Donovan. 2003. Improving students' learning by developing their understanding of assessment criteria and processes. Assessment and Evaluation in Higher Education 28: 147-64.

Sadler, D.R. 1989. Formative assessment and the design of instructional systems. Instructional Science 18: 119-44.

Sadler, D.R. 1998. Formative assessment: Revisiting the territory. Assessment in Education 5: 77-84.

Sadler, D.R. 2005. Interpretations of criteria-based assessment and grading in higher education. Assessment and Evaluation in Higher Education 30: 175-94.

Sadler, D.R. 2009. Indeterminacy in the use of preset criteria for assessment and grading. Assessment and Evaluation in Higher Education 34: 159-79.

Sadler, D.R. 2010. Beyond feedback: Developing student capability in complex appraisal. Assessment and Evaluation in Higher Education 35: 535-50.

Sergeant, J., K. Mann, C. Van der Vleuten, and J. Metsemakers. 2008. 'Directed' self-assessment: Practice and feedback within a social context. Journal of Continuing Education in the Health Professions 28: 47-54.

Shute, V.J. 2008. Focus on formative feedback. Review of Educational Research 78: $153-89$.

Sluijsmans, D.M.A., S. Brand-Gruwel, J.J.G. Van Merriënboer, and R. Martens. 2004. Training teachers in peer-assessment skills: Effects on performance and perceptions. Innovations in Education and Teaching International 41: 59-78.

Sluijsmans, D.M.A., G. Straetmans, and J.J.G. Van Merriënboer. 2008. Integrating authentic assessment with competency based learning: The protocol portfolio scoring. Journal of Vocational Education and Training 60: 157-72.

Tan, K.H.K. 2007. Conceptions of self-assessment: What is needed for long-term learning? In Rethinking assessment in higher education: Learning for the longer term, ed. D. Boud and N. Falchikov, 181-97. New York, NY: Routledge.

Tan, K.H.K. 2008. Qualitatively different ways of experiencing student self-assessment. Higher Education Research and Development 27: 15-29.

Taras, M. 2003. To feedback or not to feedback in student self-assessment. Assessment and Evaluation in Higher Education 28: 549-65.

Taras, M. 2005. Assessment - summative and formative - some theoretical reflections. British Journal of Educational Studies 35: 466-78.

Tillema, H.H., J.W.M. Kessels, and F. Meijers. 2000. Competencies as building blocks for integrating assessment with instruction in vocational education: A case from The Netherlands. Assessment and Evaluation in Higher Education 25: 265-78.

Van Gennip, N.A.E., M.S.R. Segers, and H.H. Tillema. 2009. Peer assessment for learning from a social perspective: The influence of interpersonal variables and structural features. Educational Research Review 4: 41-54.

Van Gog, T., F. Paas, and J.J.G. Van Merriënboer. 2008. Effects of studying sequences of process-oriented and product-oriented worked examples on troubleshooting transfer efficiency. Learning and Instruction 18: 211-22.

Van Merriënboer, J.J.G. 1997. Training complex cognitive skills. Englewood Cliffs, NJ: Educational Technology.

Van Merriënboer, J.J.G., O. Jelsma, and F. Paas. 1992. Training for reflective expertise: A four-component instructional design model for complex cognitive skills. Educational Technology Research and Development 40: 23-43.

Van Merriënboer, J.J.G., and D.M.A. Sluijsmans. 2009. Toward a synthesis between cognitive load theory and self-directed learning. Educational Psychology Review 21: 55-66. 